\title{
A EDUCAÇÃO PROFISSIONAL EMANCIPATÓRIA
}

Alexsandra Teixeira ${ }^{1}$ Evaldo Luis Pauly ${ }^{2}$

\section{RESUMO}

O artigo reflete sobre as contribuições e as limitações da educação profissional de jovens em relação ao seu caráter emancipatório, no desenvolvimento tanto dos aspectos técnicos quanto das habilidades e competências pessoais e profissionais necessárias. A metodologia utilizada é o estudo documental e a interpretação de algumas produções acadêmicas e empresariais sobre a Educação Profissional, partindo do pressuposto que a educação profissional, no que diz respeito ao seu caráter emancipatório, poderá atuar de modo a contribuir não só com o aumento da empregabilidade do jovem e o consequente incremento na economia, como também contribuir para nortear a vida do aluno para o desenvolvimento de sua autossuficiência. $\mathrm{O}$ estudo, por fim, apresenta algumas evidências que indicam como a educação profissional vem agregando valor ao desenvolvimento dos jovens brasileiros e, por consequência, contribuindo com o desenvolvimento do país.

Palavras-Chave: Educação profissional. SENAI. Educação emancipatória. 


\section{INTRODUÇÃO}

É consenso que a educação está intimamente ligada ao crescimento e ao desenvolvimento econômico. Diante disto, o tema tem sido objeto de atenção em vários fóruns (UNESCO, 1995). O relatório da mesa redonda europeia dos industriais indicou que "[...] a educação deve ser considerada como um serviço prestado ao mundo econômico." (UNESCO, 1995, p. 269). Frente ao exposto, parece-nos possível verificar a hipótese de que a educação pode contribuir para a melhoria no desempenho dos profissionais, que, se melhor capacitados, estariam mais aptos para absorver, reproduzir e desenvolver tecnologias, tornando-se, portanto, mais produtivos. E, além disto, o aumento da produtividade profissional traz, como resultado, o crescimento da indústria e consequentemente o crescimento da economia nacional. Como já anunciava o Manifesto dos Pioneiros da Educação Nova de 1932, “[...] é impossível desenvolver as forças econômicas ou de produção, sem o preparo intensivo das forças culturais e o desenvolvimento das aptidões à invenção e à iniciativa." (AZEVEDO, 2010, p. 33).

Por meio de uma parceria entre o Instituto Brasileiro de Análise Social e Econômica (IBASE) e o Instituto Pólis, entre 2004 e 2005, foi realizada uma pesquisa de opinião envolvendo 8 mil jovens entre 15 e 24 anos nas Regiões Metropolitanas de Belém, Belo Horizonte, Porto Alegre, Recife, Rio de Janeiro, Salvador, São Paulo e no Distrito Federal (IBASE, 2006, p.77).A educação escolar, segundo as respostas dos jovens pesquisados, é uma das questões que mais os preocupa, atrelada a outros problemas, tais como a violência, o trabalho e a desigualdade social. Além disso, os jovens chamaram a atenção para as péssimas condições estruturais dos imóveis, equipamentos, mobiliários e materiais escolares. Destacaram ainda o distanciamento que percebem nas suas relações com os professores e até mencionaram a obsolescência das metodologias educacionais e dos currículos e materiais didáticos. Segundo eles, esta inadequação os afasta ainda mais de uma promissora carreira profissional (IBASE, 2006).

Outro documento analisado para embasar este artigo foi o relatório publicado em 2011, relativo ao programa "Destino Educação - Diferentes países, diferentes respostas”, desenvolvido pela Fundação Roberto Marinho e o Canal Futura, em parceria com o Serviço Social da Indústria - SESI, que objetivou explorar casos de países bem-sucedidos no Programa Internacional de Avaliação de Alunos (PISA) - coordenado pela Organização para Cooperação e Desenvolvimento Econômico(OCDE).O objetivo do programa foi apresentar experiências que estimulassem inovações nas escolas brasileiras. Os países que fizeram parte do programa foram: Finlândia, Coreia do Sul, Chile, China (com ênfase em Xangai) e Canadá. Para escolhê-los, foram considerados seus desempenhos nas edições 2000, 2003 e 2006 do PISA com base nos relatórios produzidos pela OCDE. $\mathrm{E}$, além disso, com vistas a selecionar um país da América Latina, foram analisadas todas as nações desse continente que participaram em duas ou mais edições do PISA, em que se destacou o Chile (FUNDAÇÃO; CANAL FUTURA; SESI, 2011).

Segundo a pesquisa, a Finlândia classificou-se em primeiro lugar no desempenho em Leitura nas edições de 2000 e 2003 do PISA. Em 2006, embora a nota média do país tenha aumentado, os finlandeses ficaram em segundo, perdendo 
para a Coreia do Sul. A nação oriental, por sua vez, classificou-se em oitavo lugar no PISA 2000, passando ao segundo melhor desempenho em 2003. O relatório demonstra que:

Finlândia e Coreia do Sul destacam-se não apenas pela excelência, mas também pelo alto grau de equidade de seus resultados. Estão entre os cinco países que no PISA 2006 apresentaram a maior proporção de estudantes (mais de 20\%) nos níveis mais elevados da escala de proficiência em Leitura (níveis 5 e 6 ) e a menor proporção de estudantes de 15 anos com desempenho abaixo do nível 2 (em torno de 10\%). (FUNDAÇÃO; CANAL FUTURA; SESI, 2011, p.6)

O estudo, entre outros fatores, destacou o salto no desempenho da Coreia do Sul, devido a “[...] uma mudança curricular que introduziu maior número de horas semanais de aulas de leitura, interpretação, produção de textos e provas dissertativas em substituição aos testes padronizados [...]"(FUNDAÇÃO; CANAL FUTURA; SESI,2011,p.8), anteriormente utilizados pelo país. O mesmo entendimento se confirma com Miltons e Michelon (2008), pois, segundo eles, a Coréia do Sul só alcançou altos índices de progresso e desenvolvimento por meio do forte investimento em uma educação de qualidade, que fez com que o ensino no país estivesse ao alcance de todos. Segundo os autores, o país atingiu

[...] a universalização da educação básica no final da década de 1960 e do ensino médio na década de 1980 . Os anos de 1980 e 1990, ainda assistiram a uma forte expansão das matrículas em nível superior. A evidência empírica mostra que a Coréia atingiu um elevado nível de qualificação de sua mão-de-obra por meio da educação formal. (MILTONS; MICHELON, 2008, p. 2)
Em relação à reforma educacional finlandesa e a consequente contribuição ao país, Monteiro (2013, p. 32) mencionou que a "[..] escola finlandesa é a prova da compatibilidade entre equidade, qualidade e competitividade [...]” indicando que o "[...] fator de sucesso da escola finlandesa mais frequentemente destacado é o estatuto profissional e social da profissão docente." O autor destaca a educação profissional na Finlândia, atribuindo como principais características a estrutura modular, a flexibilidade e a liberdade de escolha do estudante. Acrescenta que a escola secundária profissional está dividida em duas alternativas: a aprendizagem profissional ou a qualificação com base em competências adquiridas. Em relação à aprendizagem profissional, Monteiro (2013) explica que esta ocorre em parte no ambiente profissional e em parte na escola, pois existem duas alternativas para a escola secundária profissional:

$$
\begin{aligned}
& \text { [...] a aprendizagem profissional } \\
& \text { no local de trabalho, acompanhada } \\
& \text { de tempos de formação teórica } \\
& \text { numa escola, através de um contrato } \\
& \text { entre o aprendiz, o empregador e a } \\
& \text { autoridade escolar; e a qualificação } \\
& \text { com base em competências adquiridas. } \\
& \text { Embora não haja requisitos formais } \\
& \text { para a candidatura aos testes de } \\
& \text { competências, a maior parte dos } \\
& \text { candidatos frequentam cursos de } \\
& \text { formação complementar para a sua } \\
& \text { realização. O sistema é supervisionado } \\
& \text { por Comitês Nacionais de Educação } \\
& \text { e Formação, criados pelo Ministério } \\
& \text { e formados por representantes } \\
& \text { das entidades patronais, dos } \\
& \text { trabalhadores e da profissão docente. } \\
& \text { (MONTEIRO, 2013, p. 30) }
\end{aligned}
$$

Diante dos aspectos até aqui apresentados, a escolha deste tema deu-se em virtude dos resultados obtidos na pesquisa do IBASE (2006), quanto à preocupação de jovens brasileiros, entre 15 e 24 anos, com a carreira profissional, emergindo como questão central: $\mathrm{O}$ quanto 
a educação profissional pode contribuir para nortear a vida do aluno em relação ao desenvolvimento de sua autossuficiência?

Portanto, ao analisar esta questão, objetiva-se verificar as possibilidades de oferta de uma educação profissional de qualidade que favoreça o processo emancipatório do aluno, contribuindo não só com o aumento da empregabilidade dos jovens como o consequente incremento na economia e o desenvolvimento do país. Ao enfrentar essa questão, pretende-se que o artigo ofereça, como objetivo específico, aos docentes da Educação Profissional argumentos humanistas para a formação dos trabalhadores, além dos necessários conteúdos técnicos.

$\mathrm{O}$ artigo resultou de uma pesquisa qualitativa, compreendendo um estudo documental, bem como a interpretação de algumas produções acadêmicas e empresariais sobre a Educação Profissional. A interpretação partiu de uma revisão das expectativas da indústria brasileira em relação à educação de seus profissionais, considerado como um dos fatores-chave para o aumento da competitividade. Nesse sentido, o artigo avalia também a preocupação dos jovens com suas carreiras profissionais e, portanto, busca-se verificar a condição da oferta de educação profissional de qualidade que favoreça o aumento da empregabilidade dos jovens alunos e o consequentemente desenvolvimento do país.

Este artigo está dividido em seis seções: as seções 2 e 3 apresentam um rápido histórico da educação profissional no Brasil, para, em seguida, destacar algumas expectativas educacionais oriundas de lideranças da indústria brasileira. Na seção 4, descrevemos a análise dos resultados obtidos neste estudo. $\mathrm{Na}$ seção 5 , as considerações finais e, na última seção, serão apresentadas as referências do artigo. Desse modo, este texto pretende demonstrar o quanto a educação profissional pode cooperar para o desenvolvimento da autossuficiência dos jovens alunos.

\section{BREVE RETOMADA HISTÓRICA DA EDUCAÇÃO PROFISSIONAL NO BRASIL}

Em um breve histórico da educação profissional no Brasil, constata-se que, no século XIX, predominava a educação propedêutica voltada para as elites e sua formação como dirigentes. Até que, em 1809, D. João VI propôs a criação do Colégio das Fábricas, considerado pelos historiadores como o início da educação profissional no Brasil (CNE/CEB, 1999).

A primeira notícia de um esforço governamental em direção à profissionalização data de 1809, quando um Decreto do Príncipe
Regente, futuro D. João VI, criou o "Colégio das Fábricas", logo após a suspensão da proibição de funcionamento de indústrias manufatureiras em terras brasileiras. Posteriormente, em 1816, era proposta a criação de uma "Escola de Belas Artes", com o propósito de articular o ensino das ciências e do desenho para os ofícios mecânicos. Bem depois, em 1861, foi organizado, por Decreto Real, o "Instituto Comercial do Rio de Janeiro", cujos diplomados tinham preferência no preenchimento de cargos públicos das Secretarias de Estado. (CNE/CEB, 1999, p.8) 
Assim, então, iniciam-se, no decorrer do século $\mathrm{XIX}$, as diversas instituições que tinham como foco o atendimento às crianças em situação de vulnerabilidade econômica e social, direcionadas para o ensino das primeiras letras e a iniciação aos ofícios, como tipografia, carpintaria, sapataria, tornearia, dentre outras (CNE/ CEB, 1999).

Diante da revisão da literatura até aqui desenvolvida, parece-nos possível propor que a educação profissional no Brasil nascia naquela época com um propósito muito mais assistencialista do que visando à garantia da produtividade. Além disso, considerando que, à época, conviveram os dois modelos de educação, com propósitos distintos, sendo uma mais intelectualizada e voltada para as elites e a outra mais utilitária e voltada às classes menos favorecidas, parece ter aí se estabelecido uma relação divergente entre as duas formas de educação.

Desde 1932, por conta da divergência mencionada anteriormente, a educação profissional vem sendo criticada pelos pedagogos brasileiros, conforme demonstrado por Azevedo (2010), no Manifesto dos Pioneiros da Educação Nova, que propunha:

A escola secundária, unificada para se evitar o divórcio entre os trabalhadores manuais e intelectuais" de modo a garantir a formação de uma cultura geral do povo brasileiro para, então, realizar "posterior bifurcação" entre uma seção de preponderância intelectual [...], e em seção de preferência manual, ramificada por sua vez, em ciclos escolas ou cursos destinados à preparação às atividades profissionais, decorrentes da extração de matérias-primas [...] da elaboração das matérias-primas [...] e da distribuição dos produtos elaborados [...]. (AZEVEDO, 2010, p. 54)
Conforme o histórico do Parecer 16/99, ainda no início do século XX, a formação educacional profissionalizante:

$$
\begin{aligned}
& {[\ldots] \text { continuou mantendo, }} \\
& \text { basicamente, o mesmo traço } \\
& \text { assistencial do período anterior, isto } \\
& \text { é, o de um ensino voltado para os } \\
& \text { menos favorecidos socialmente, para } \\
& \text { os “órfãos e desvalidos da sorte”. A } \\
& \text { novidade será o início de um esforço } \\
& \text { público de organização da formação } \\
& \text { profissional, migrando da preocupação } \\
& \text { principal com o atendimento de } \\
& \text { menores abandonados para uma outra, } \\
& \text { considerada igualmente relevante, a } \\
& \text { de preparar operários para o exercício } \\
& \text { profissional. (CNE/CEB, 1999, p. } 9 \text { ) }
\end{aligned}
$$

No ano de 1906, “[... ] o ensino profissional passou a seratribuição do Ministério da Agricultura, Indústria e Comércio [...]", implementando-se, então, o incentivo ao desenvolvimento do ensino industrial, comercial e agrícola. Nessa mesma década,foram instaladas várias escolas-oficinas destinadas à formação profissional de ferroviários (CNE/CEB, 1999, p. 9).

Já na década de 20, a Câmara dos Deputados propôs “[...] a extensão do ensino profissional tanto aos pobres quanto aos ricos [...]", sendo instituída assim uma comissão especial que se debruçous sobre o tema educação e criou a Associação Brasileira de Educação,importante polo irradiador do movimento renovador da educação brasileira por meio das Conferências Nacionais de Educação. Como apresentado anteriormente, ainda em 1932, foi lançado o Manifesto dos Pioneiros da Educação Nova, buscando sugerir rumos às políticas públicas de educação, de modo que promovessem as mesmas oportunidades para todos. Dois anos depois, a Constituição de 1934 procurou estabelecer como competências privativas da União “[...] traçar Diretrizes da Educação Nacional 
[...]" (art. 5o, inciso XIV) e "[...] fixar o Plano Nacional de Educação [...]” - art. 150, alínea “a” (CNE/CEB, 1999, p. 10).

Em 1942, quando se iniciou o movimento de aprovação do conjunto das Leis Orgânicas do Ensino, também conhecidas como Reforma de Capanema e com a organização da Rede Federal de Estabelecimentos de Ensino Industrial, por meio de decreto-lei, o ensino profissional passa a se consolidar no Brasil, embora ainda continuasse a ser preconceituosamente considerado como uma educação de segunda categoria (CNE/CBE, 1999).

\section{No conjunto das Leis Orgânicas da Educação Nacional, o objetivo do ensino secundário e normal era o de "formar as elites condutoras do país" e o objetivo do ensino profissional era o de oferecer "formação adequada aos filhos dos operários, aos desvalidos da sorte e aos menos afortunados, aqueles que necessitam ingressar precocemente na força de trabalho". A herança dualista não só perdurava como era explicitada. (CNE/CBE, 1999, p. 12)}

Esse preconceito permanecera ao longo de décadas. Por exemplo, no Rio Grande do Sul, ainda em meados dos anos 70, isso se evidencia no depoimento da Dr. ${ }^{a}$ Maria Simões Pires, representante do MAPA (Movimento Assistencial de Porto Alegre), ao assegurar que a primeira iniciativa de sua instituição na área da criança e do adolescente consistia na "[...] ajuda ao menor engraxate - estamos atendendo a 200 engraxates, que têm uniforme, caixas, alimentação - e já estamos também com assistência dentária e médica, vamos agora dar aulas também." (COMISSÃO ESPECIAL, 1976, p. 229).
A superação deste preconceito se inicia com a promulgação da Constituição Federal de 1988 e com a respectiva normatização da Lei de Diretrizes e Bases da Educação Nacional, Lei no 9.394/96, pela qual se configura o “[...] ensino médio como uma etapa de consolidação da educação básica, de aprimoramento do educando [...]”, de forma a continuar seu aprendizado para o trabalho e a cidadania. Refletindo assim, de acordo com o Parecer 16/99 do Conselho Nacional de Educação, aprovado em 5 de outubro de 1999, que tratou acerca das Diretrizes Curriculares Nacionais para a Educação Profissional de Nível Técnico, observa-se que essa “[...] concepção representa a superação do enfoque assistencialista e economicista da educação profissional, bem como do preconceito social que a desvalorizava”. Deste ponto em diante, após o ensino médio, tanto o ensino técnico e tecnológico quanto os cursos de graduação passaram a ser considerados como cursos de educação profissional (CNE/CEB, 1999, p. 15).

Entretanto, embora demonstrado os avanços efetivos da educação profissional no Brasil, revisitando alguns pesquisadores que se debruçaram sobre o tema, fica evidente ainda que a percepção de herança dualista ainda perdura. Sem o objetivo de revisão literária, mas apenas para enriquecer a reflexão, destacam-se algumas abordagens apresentadas nos parágrafos a seguir.

Para Kuenzer (2007), a formação de trabalhadores e cidadãos no Brasil constitui-se historicamente a partir de uma "dualidade estrutural", uma vez que, ao longo da história, demonstrou uma nítida demarcação de trajetória educacional para as elites e outra para os trabalhadores. 
Aideia era a de que os cursos profissionalizantes eram destinados aos jovens menos favorecidos e que não fossem seguir carreiras universitárias, enquanto que às elites cabia o acesso às ciências e humanidades, que dariam suporte às atividades intelectuais, e que os levaria assim ao ensino superior. Conforme Saviani (2007), o caráter dualista reforça que cada ramo ou tipo de ensino está atrelado àquilo que é requerido pela organização social. Gramsci (1985), por sua vez, defendia a ideia de "escola única", para garantir uma educação básica comum a todos os jovens. $\mathrm{O}$ autor sugere que a formação profissional organiza e promove a formação dos trabalhadores, ignorando-lhes a dimensão humana ao defender os interesses do capital.

Destaca-se também Araújo (2006), que aposta em uma escola unitária, uma formação que tenha o homem como centro e não o mercado, conciliando o trabalho, a ciência, a cultura e a tecnologia.Já Frigotto, Ciavatta e Ramos (2005) alertam quanto ao aspecto contingencial e emblemático de uma série de programas isolados que contribuíram para a visão dicotômica da educação profissional, tais como o PROEJA, PROEP, PROJOVEM, dentre outros, que possuíram um papel muito mais comunitário do que profissional.

\section{EXPECTATIVAS EDUCACIONAIS DA INDÚSTRIA BRASILEIRA}

Para a Confederação Nacional da Indústria (CNI), instituição máxima de organização do setor industrial que coordena as 27 federações de indústria dos estados e do Distrito Federal, às quais estão filiados 1.016 sindicatos patronais, a educação é a base para a construção de uma indústria inovadora e competitiva. Segundo o relato dos empresários, “[...] equipes educadas e engenheiros bem formados utilizam melhor os equipamentos, criam soluções para os problemas do dia a dia, adaptam processos e produtose desenvolvem e implementam inovações."(CNI, 2013, p. 27).

O Mapa Estratégico da Indústria 2013-2022 indica que a indústria e o Brasil devem, na próxima década, aumentar os níveis de produtividade e eficiência para alcançar um grau mais elevado de competitividade. Esse caminho a percorrer é fruto de debates e contribuições de mais de 500 pessoas, entre empresários, executivos, acadêmicos e presidentes de associações nacionais setoriais e federações de indústrias. O Mapa identifica dez fatores-chave para alavancar a competitividade brasileira. Um dos fatores destacados pela liderança empresarial é que "[...] na base de tudo temos a educação. Uma sociedade educada é essencial na construção de instituições e de um ambiente favorável aos negócios. A educação também é o principal insumo para a inovação.” (CNI, 2013, p. 24).

Para cada fator chave, o Mapa aponta uma macrometa, que é o principal resultado a ser alcançado até 2022, e o indicador, cuja evolução mostrará se o país e a indústria estão no caminho da competitividade com sustentabilidade. 
Entre as principais metas do Mapa Estratégico da Indústria 2013-2022 está a melhoria da qualidade da educação. Conforme apresentado na Figura 1, a proposta da indústria é ousada e propõe que a nota média dos brasileiros no PISA alcance 435 pontos em 2015 e chegue a 480 pontos em 2021 (CNI, 2013).

Figura 1: Macrometa educação proposta pela indústria

\begin{tabular}{ll} 
Macrometa & Melhorar a qualidade da educação \\
\hline Indicador & $\begin{array}{l}\text { Posição do Brasil no ranking do PISA } \\
\text { (leitura + matemática + ciências) }\end{array}$ \\
\hline
\end{tabular}

Descrição Nota média do PISA

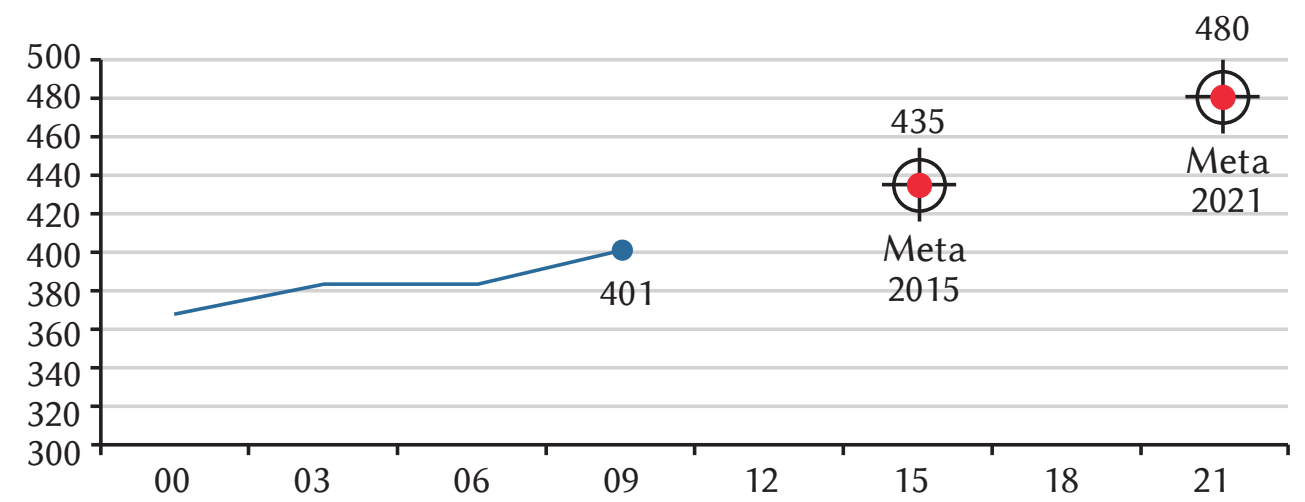

*A meta é passar da 54a posição do ranking de 2009 para a 43a em 2021. Para isso, a nota média do Brasil deverá passar de 401, em 2009, para 480, em 2021. Note-se que as provas são realizadas de três em três anos.

**480 é próximo à nota média da Espanha na última avaliação (484 em 2009).

Fonte: CNI (2013, p. 28)

Mesmo considerando a facilidade de acesso da população à escola, os dados indicam para uma baixa qualidade da educação básica. Por isso, as empresas apontam a necessidade de ampliar ainda mais a oferta de ensino profissional, visando ampliar a capacidade de inovação e produtividade das empresas. A proposta é que, em 2022, a indústria brasileira disponha de profissionais mais qualificados, com nível próximo ao dos países mais desenvolvidos, tendo como uma das alterativas a educação profissional orientada para as necessidades do mercado de trabalho. Também afirmam que a maior oferta de profissionais adaptados aos novos modelos de produção e novas tecnologias aliada aos investimentos das empresas em capacitações produzirão um ambiente propício à inovação e colocarão a indústria em condições de enfrentar a crescente competição internacional (CNI, 2013).

Em termos teóricos, na perspectiva governamental, a Educação Profissional, ao longo da história republicana brasileira, parece marcada pela contradição entre, de um lado, o discurso governamental de reconhecimento de seu papel estratégico no desenvolvimento econômico do país e, de outro, uma prática constante de desvalorização desta Educação pelos sistemas de ensino governamentais. A pesquisa acadêmica sobre a Educação Profissional geralmente explica esse histórico a partir da contradição entre os interesses dos trabalhadores e os das classes dominantes.Frigotto, Ciavatta, Ramos (2005,p. 
1089) avaliam que, no primeiro governo Lula, essa contradição, novamente, “[...] representa, na verdade, a disputa entre os setores progressistas e conservadores da sociedade brasileira pela hegemonia nesse campo." $\mathrm{Na}$ perspectiva das lideranças industriais, a CNI (2013) acentua, nas últimas décadas, a necessidade de os sistemas de ensino oferecerem, de fato, uma qualificada Educação Profissional como condição político-pedagógica para a inserção autônoma e competitiva da indústria nacional no mercado globalizado.

\section{APRESENTAÇÃO E ANÁLISE DOS RESULTADOS}

A partir do embasamento teórico exposto anteriormente, parece que a análise generalizante sobre as contradições da Educação Profissional não se verifica no caso concreto da liderança empresarial representada pela CNI (2013), segundo a qual há uma histórica reivindicação dos industriais pela qualificação profissional dos trabalhadores através da educação. Parece procedente, portanto, confrontar as decisões governamentais, representadas pelo Parecer $n^{\circ}$ 16/1999, do Conselho Nacional de Educação, estabelecendo as Diretrizes Curriculares Nacionais para a Educação Profissional de Nível Técnico (CNE/CEB, 1999) e pela alteração no que se refere aos capítulos da LDB sobre a Educação Profissional realizada pelo Decreto no 5.154/2004 (BRASIL, 2004), com o posicionamento político da CNI em seu Mapa estratégico da indústria 2013-2022 (CNI, 2013) e da FIERGS (2016), bem como, com o estudo comparativo entre a educação brasileira e a internacional realizada pelo Serviço Social da Indústria (FUNDAÇÃO; CANAL FUTURA; SESI, 2011). O confronto entre estes documentos busca responder à questão central deste artigo: o quanto a educação profissional pode contribuir para nortear a vida do aluno em relação ao desenvolvimento de sua autossuficiência? O artigo, nesta seção, apresenta algumas evidências que indicam como a educação profissional vem agregando valor ao desenvolvimento dos jovens brasileiros e, por consequência, contribuindo com o desenvolvimento do país.

Conforme exposto nas seções anteriores, mesmo em meio ao cenário em que a educação profissional não era percebida por todos, como aquela que oportunizaria aos alunos o alcance da autonomia, surgiram iniciativas privadas de educação profissional, dentre as quais é possível destacar o Serviço Nacional de Aprendizagem Industrial (SENAI), em 1942, e o Serviço Nacional de Aprendizagem do Comércio (SENAC), em 1946. Especificamente em relação à criação do SENAI, em 22 de janeiro de 1942, pelo Decreto-Lei 4.048 e também considerando o até aqui foi exposto, é possível depreender que a indústria já percebia, naquela época, que a educação possui papel essencial para alcançar o desenvolvimento, pois o decreto estabelecia que a nova instituição de educação profissional fosse mantida com recursos dos próprios empresários e administrada pela Confederação Nacional da Indústria.

Mais tarde, no fim da década de 50, em meio à aceleração do processo de industrialização do Brasil, o SENAI já estava presente em quase todo o território nacional e começava a buscar, no exterior, a formação para seus técnicos. 
Foi a partir de então que passou a ser referência de uma educação profissional de qualidade em toda a América Latina, firmando parcerias e cooperação para a criação de instituições similares na Venezuela, Chile, Argentina, Peru, Guatemala, Guiné Bissau, Paraguai, Cabo Verde, Jamaica, São Tomé e Príncipe, Angola e Timor Leste. Mantem ainda parcerias com 53 instituições internacionais, como o British Council, do Reino Unido, o Massachussetts Institute of Technology, dos Estados Unidos, o Swedisth ICT, da Suécia, o instituto alemão Fraunhofer,entre outros, evidenciado assim seu potencial de contribuição, inclusive para outros países, e o interesse em trazer para o Brasil as melhores práticas educativas dos países mais avançados. Em junho de 2016,

\section{[...] o SENAI foi reconhecido como uma das três instituições mais importantes do Hemisfério Sul, cujo objetivo é assegurar educação de qualidade entre os integrantes da Cooperação Sul-Sul, um mecanismo de países emergentes do hemisfério sul, destinado a dar respostas conjuntas a desafios comuns. (FIERGS, 2016).}

Em continuidade e objetivando promover uma reflexão acerca de outros pontos de vista que evidenciam as contribuições da educação profissional, apresenta-se um recorte do estudo realizado no Centro Federal de Educação Tecnológica de Minas Gerais (CEFET-MG), que analisa o depoimento de 20 professores de instituições de educação profissional da Região Metropolitana de Belo Horizonte.
A pesquisa envolveu docentes que atuam em escolas privadas ou do Sistema $\mathrm{S}^{1}$, bem como, em escolas públicas, tanto federais, estaduais ou municipais. Dentre os objetivos da pesquisa, um deles foi analisar as concepções de educação profissional, que orientavam a prática docente dos entrevistados, conforme fica claro que os entrevistados tiveram suas vidas positivamente influenciadas por conta da educação profissional: [...] a escola surge com uma enorme vitalidade nos depoimentos quando eles se referem aos cursos técnicos realizados. Alunos de instituições diversas [...], todos ressaltam o valor de sua formação técnica. Há uma maior ênfase a esse fato nos casos de sujeitos que fizeram cursos de horário integral, [...] Os depoimentos dão conta, de vocações para áreas técnicas, em alguns casos verdadeiras paixões. (BURNIER et al, 2007, p. 350)

Durante a narrativa da pesquisa, também foi possível destacar, em vários momentos, que os entrevistados possuíam uma visão muito positiva a respeito de si mesmos, especialmente quando as pesquisadoras constatam serem "[...] comuns as falas que utilizam termos como 'sucesso', 'vitorioso','consegui', apontando para um olhar evolucionista com relação à sua própria história.” (BURNIER et al., 2007, p.350)

Na ocasião em que as pesquisadoras propuseram uma definição, ou solicitaram a concepção de educação para cada entrevistado, identificaram que os professores entrevistados demonstraram o entendimento de que a educação profissional ultrapassa o conceito técnico, que muitos atrelaram educação ao mercado de trabalho,

\footnotetext{
1 "Termo que define o conjunto de organizações das entidades corporativas voltadas para o treinamento profissional, assistência social, consultoria, pesquisa e assistência técnica, que, além de terem seu nome iniciado com a letra S, têm raízes comuns e características organizacionais similares. Fazem parte do sistema S: Serviço Nacional de Aprendizagem Industrial (Senai); Serviço Social do Comércio (Sesc); Serviço Social da Indústria (Sesi); e Serviço Nacional de Aprendizagem do Comércio (Senac). Existem ainda os seguintes: Serviço Nacional de Aprendizagem Rural (Senar); Serviço Nacional de Aprendizagem do Cooperativismo (Sescoop); e Serviço Social de Transporte (Sest)". (GLOSSÁRIO, s.d.)
} 
à transmissão de conteúdos, à transmissão de conhecimentos práticos da profissão, mas que também havia entre aqueles professores uma grande preocupação com questões quanto ao posicionamento doaluno enquanto profissional e ao mesmo tempo procuravam desenvolver em suas aulas questões como: saber pensar, construir atitudes, trabalhar a curiosidade, nortear a vida do aluno e trabalhar a autossuficiência. Identificaram também que estes aspectos, além de extrapolarem o conceito de educação técnica, ainda ultrapassam a formação direcionada apenas para o mercado de trabalho, demonstrando que os professores também apresentavam uma preocupação com a formação mais ampla do aluno (BURNIER et al., 2007). Neste sentido, em paralelo aos aspectos técnicos, esta ideia de os professores procurarem desenvolver nos alunos habilidades pessoais remete à hipótese de que os professores entrevistados realmente acreditavam no potencial de aprendizagem e de sucesso profissional de seus alunos como agentes transformadores.

Outro atributo que se destaca na pesquisa é o fato de que "[...] no caso da educação profissional, fica evidente que as histórias de vida desses docentes constituem poderosas conexões que os aproximam de seus alunos." As autoras indicam que os professores possuem histórias de vida semelhantes às de seus alunos, que assim, como eles, à procura de uma oportunidade, identificaram no mundo do trabalho acesso a melhores condições de vida.Um dos professores entrevistados mencionou que preparava os alunos para que fossem agentes transformadores, com objetivos, que tivessem ideias próprias, que gerem em si,que produzam, que deem opiniões e que modifiquem. Este professor destacou o desejo de que seus alunos, de alguma forma, sejam agentes de melhora do mundo. Analisando a concepção de educação profissional sobre a ótica da pesquisa realizada pelo Centro Federal de Educação Tecnológica de Minas Gerais, observa-se que esta relativiza a afirmação de que ainda se mantém a dualidade no âmbito da educação profissional (BURNIER et al, 2007, p.356).

Além disso, o próprio Decreto no 5.154 , de 23 de julho de 2004, ao manter as ofertas de educação profissional de modo concomitante e subsequente, trouxe de volta a possibilidade de integrar o ensino regular à educação profissional e ao se manter a existência de sistemas e redes distintas, possibilitou a coexistência de ensino propedêutico e, a profissionalização enquanto etapa autônoma e ao mesmo tempo a integração entre ambas se assim o aluno decidir (BRASIL, 2004).

Assim, ao contrário do apontado por Araújo (2006), Saviani (2007), Kuenzer (2007), Frigotto, Ciavatta e Ramos (2005) e Gramsci (1985), a educação profissional brasileira,se bem organizada e corretamente gerida, poderá contribuir para nortear a vida do aluno em relação ao desenvolvimento de sua autossuficiência e, além disso, objetivando atender às expectativas dos empresários, por consequência, contribuir para o desenvolvimento do país, a exemplo do que ocorrera com países como Finlândia, Coreia do Sul, China e Canadá, demonstrado no relatório "Destino Educação - Diferentes países, diferentes respostas", analisado na primeira seção. 


\section{CONSIDERAÇÕES FINAIS}

A análise e interpretação dos documentos mencionados anteriormente parece indicar que as contradições apontadas pela pesquisa acadêmica sobre Educação Profissional empreendidas por Araújo (2006), Saviani (2007), Kuenzer (2007), Frigotto, Ciavatta e Ramos (2005) e Gramsci(1985) não são suficientes para esgotar a complexa relação entre alguns setores mais dinâmicos da indústria e a formação cultural necessária aos profissionais demandados por estes setores. A educação profissional brasileira pode avançar,se melhor articulada, organizadae gerida de forma democrática, eficaz e integrada com a representação patronal e laboral destes setores mais dinâmicos da indústria nacional. Talvez essa nova articulação, organização e gestão possam contribuir para nortear a vida do aluno em relação ao desenvolvimento de sua autossuficiência, tal como propunha a questão de investigação deste artigo inspirada pela pesquisa do IBASE (2006). Ao contrário, portanto, de afirmar que a Educação Profissional está perpassada pela contradição entre as classes dominantes e as dominadas, também é possível afirmar que pode haver, no caso específico da educação profissional de qualidade, uma possível coincidência entre os interesses educacionais e o crescimento pessoal dos trabalhadores com as expectativas dos empresários, por consequência, contribuindo para o desenvolvimento do país, a exemplo do que ocorrera com países como Finlândia, Coreia do Sul, China e Canadá, demonstrado no relatório relativo ao programa "Destino Educação - Diferentes países, diferentes respostas”, analisado na primeira seção deste artigo.

A seção 2 apresentou um breve histórico da educação profissional brasileira, destacando, na seção 3, algumas expectativas educacionais de lideranças da indústria que foram confrontadas na seção 4. Desse modo, o artigo demonstrou o quanto a educação profissional pode cooperar para o desenvolvimento da autossuficiência dos jovens alunos, contribuindo, ao mesmo tempo, para inserção soberana da indústria nacional no mercado globalizado.

Este artigo apresentou uma reflexão acerca das possibilidades de oferta de uma educação profissional de qualidade, que venha a favorecer um processo emancipatório dos alunos, na pretensão de diminuir a preocupação de jovens brasileiros em relação a uma oportunidade no mercado de trabalho. Pretende-se, também, disponibilizar subsídios aos docentes, para que possam, em seus fóruns, promover discussões sobre como preservar e até mesmo melhorar as contribuições que a educação profissional possa vir a ter na busca de um sistema educacional brasileiro, com níveis técnicos próximos ao dos países mais desenvolvidos, sem perdero objetivo de formação humana que caracteriza qualquer processo educacional, inclusive, o da educação profissional. Essa formação técnica, conclui-se, deve atender também às questões de formação humana, como foi apontado na introdução deste artigo, na referência à pesquisa do Instituto Pólis, acerca da preocupação dos jovens em relação à violência, ao trabalho e à desigualdade social, às péssimas condições estruturais que identificavam nos contextos educacionais em que estavam inseridos. Portanto, não faz mais sentido manter a ideia de dualidade no âmbito da educação profissional entre a formação humana e técnica. 


\section{ANALYTICAL MODELS APPLIED TO COST CONTROL IN THE MANAGEMENT OF PRODUCTION AND OPERATIONS}

\begin{abstract}
This article reflects on the contributions and the limitations of professional education of young people in relation to theiremancipatorycharacter in the development ofboth technicalaspects and the necessary personaland professional skills and competences. The methodology used is the documentary study and interpretation of some academicandbusiness productions on Professional Education, based on the assumption that professional education, with regard to its emancipatory character, can act in a way that contributes not only to increase of employability of the young people and consequent increase in the economy, as well as to contribute to guiding the life of the students to their self-sufficiency development. Thestudy, finally, presents someevidences that indicate how the professionaleducation has benefit to the development of the Brazilian young people and consequently contributing to the development of the country.
\end{abstract}

KEYWORDS: Professional

education. SENAI.

Emancipatory education.

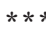

\section{REFERÊNCIAS}

ARAÚJO, Ronaldo Marcos de Lima. A regulação da educação profissional do governo Lula: Conciliação de interesses ou espaço para a mobilização. In: GEMAQUE e LIMA (org.). Políticas educacionais: $\mathrm{O}$ governo Lula em questão. Belém - PA. CEJUP, 2006. p. 191-213.

AZEVEDO, Fernando de et al. Manifestos dos pioneiros da Educação Nova (1932) e dos educadores 1959. Recife: Fundação Joaquim Nabuco, Editora Massangana, 2010. Disponível em: <https://goo.gl/O8RYYJ>. Acesso em: 07 abr. 2017.

BRASIL. Constituição da República dos Estados Unidos do Brasil, de 16 de julho de 1934. Disponível em: <https://goo.gl/dYNCTM>. Acesso em: 14 jun. 2017.

BRASIL. Decreto no 5.154, de 23 de julho de 2004. Regulamenta o $\$ 2^{\circ}$ do art. 36 e os arts. 39 a 41 da Lei no 9.394, de 20 de dezembro de 1996, que estabelece as diretrizes e bases da educação nacional, e dá outras providências. Disponível em: $<$ https://goo.gl/k4BwIp>. Acesso em: 14 jul. 2017.

BURNIER, Suzana et al. Histórias de vida de professores: o caso da educação profissional. Revista Brasileira de Educação, Rio de Janeiro, v. 12, n. 35, p. 343 - 358, mai./ago. 2007. Disponível em: <https://goo.gl/HSW5Sg>. Acesso em: 07 abr. 2017.

COMISSÃO ESPECIAL constituída dos três poderes do Rio Grande do Sul criada pela lei estadual no 6.948 de 23 de dezembro de 1976. 1975 “Ano do menor” Relatório. Porto Alegre: Escola Gráfica FEPLAM, 1975. 
CNE/CEB. Conselho Nacional de Educação.

Câmara de Educação Básica. Parecer no 16/1999.

Diretrizes Curriculares Nacionais para a Educação Profissional de Nível Técnico. Brasília: CNE/

CEB, 1999. Disponível em: <https://goo.gl/GqrirR>. Acesso em: 07 abr. 2017.

\section{CONFEDERAÇÃO NACIONAL DA} INDÚSTRIA - CNI. Mapa estratégico da indústria 2013-2022. 2. ed., Brasília: CNI, 2013. Disponível em: <https://goo.gl/sL53xU>. Acesso em: 07 abr. 2017.

FIERGS. Federação das Indústrias do Estado do Rio Grande do Sul. Senai é apontado pela ONU como uma das principais instituições educacionais do hemisfério Sul. Porto Alegre, 08/06/2016 - 15:48. Disponível em: <https://goo.gl/ut4W8e>. Acesso em: 13 jul. 2017.

FRIGOTTO, Gaudêncio; CIAVATTA, Maria; RAMOS, Marise. A Política de educação profissional no governo Lula: Um percurso histórico controvertido. Educação e Sociedade, Campinas, v. 26, n. 92, p. 1087-1113, Out. 2005. Disponível em: <https://goo.g1/32URyf>. Acesso em: 07 abr. 2017.

FUNDAÇÃO Roberto Marinho; CANAL FUTURA; SESI - Serviço Social da Indústria. Destino

Educação - Diferentes países, diferentes respostas, Rio de Janeiro, 2011. Disponível em: <https://goo.g1/ DeaG3Q>. Acesso em: 29 jun. 2017.

GLOSSÁRIO Legislativo. Brasília: Senado da República, s.d.. Disponível em: <https://goo.gl/ relhLt>. Acesso em: 29 jun. 2017.

GRAMSCI, Antônio. Os intelectuais e a organização da cultura. 6. ed. São Paulo: Civilização Brasileira, 1985.
INSTITUTO BRASILEIRO DE ANÁLISE SOCIAL E ECONÔMICA - IBASE I. Instituto Pólis. Diversidade de perfis caracteriza as juventudes brasileiras. Democracia Viva, Rio de Janeiro, n. 30, p. 76-83, jan./mar. 2006. Disponível em: <https://goo.gl/ vxZhR4>. Acesso em: 07 abr. 2017.

KUENZER, Acacia (org.). Ensino médio: Construindo uma proposta para os que vivem do trabalho. 5. ed. São Paulo: Cortez, 2007.

MILTONS, Michelle Merética; MICHELON, Ednaldo. Educação e Crescimento Econômico na Coréia do Sul. In: XI Encontro Regional de Economia - ANPEC-Sul 2008. UFPR, Curitiba - PR, 26 e 27 de junho. Disponível em: <https://goo.g1/z46t6Q>. Acesso em: 07 abr. 2017

MONTEIRO, Agostinho dos Reis. Finlândia: Um Sistema de Educação Admirável. Poiésis, Tubarão, SC, v. 7, n. 11, p. 26-39, Jan/Jun, 2013. Disponível em: <https://goo.gl/9aK4gG>. Acesso em: 07 abr. 2017.

SAVIANI, Dermeval. História das ideias pedagógicas no Brasil. Campinas, SP: Autores Associados, 2007.

UNESCO. Grupo de Trabalho da Educação da ERT (European Round Table of Industrialists). Uma educação europeia: a caminho de uma sociedade que aprende. Relatório da Mesa Redonda dos Industriais Europeus. Bruxelas, 1995.

Data de recebimento:05/05/2017

Data de aprovação: 09/08/2017 


\section{SOBRE OS AUTORES}

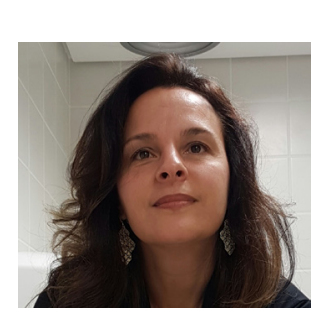

\section{Alexsandra Teixeira}

Mestranda no PPG de Educação - Centro Universitário La Salle. Especialista em Gestão e Desenvolvimento Humano pela ULBRA (2008).Licenciada em Pedagogia com Habilitação para magistério das MatériasPedagógicas do Ensino Médio e Empresarial, pela Universidade Luterana do Brasil-ULBRA (2004).Atualmente é Gerente Técnico de processos voltados à ampliação daqualidade da educação profissional no SENAI-RS. Já atuou como palestrante na V Reunión Nacional del Sistema Corporativo de Gestión de la Calidad CONALEP-Cuernavaca Morelos-México (2008). É consultora Voluntária do Programa 5S na Escola Pública - Sapucaia do Sul (2007). Participante do Programa de Desenvolvimento Técnico Pedagógico - SENAI/RS (2006). Foi examinadora Classe A do Programa Gaúcho de Qualidade e Produtividade do RS (2005) e participante do IV Congresso Ibero Americano de Qualidade na Educação - SENAI/ BR (2005).

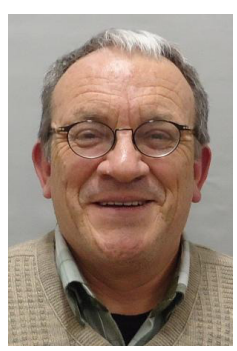

\section{Evaldo Luis Pauly}

Doutor em Educação pela Universidade Federal do Rio Grande do Sul UFRGS (2000). Docente do Programa de PósGraduação em Educação - Mestrado e Doutorado - da Universidade La Salle - UNILASALLE/ Canoas/RS.Atualmente lidera o Grupo de Pesquisa “Temáticas Lassalistas" registrado no Diretório dos Grupos de Pesquisa do CNPq e coordena a Linha de Pesquisa "Gestão, Educação e Políticas Públicas" do PPG em educação do Unilasalle. É autor de livros, capítulos e artigos em periódicos acadêmicos, conforme registrado em seu Currículo Lattes em: http://lattes.cnpq.br/7187415721002122.

\section{***}

